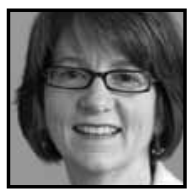

\title{
A Working Model of Mentors' Contributions to Youth Mentoring Relationship Quality: Insights From Research on Psychotherapy
}

Renée Spencer, Boston University

\begin{abstract}
Mentoring is a flexible approach to youth development that can promote positive outcomes through informal learning. Not all mentoring relationships are beneficial, however, as lower quality mentoring relationships tend to have little effect. A mentor's overall approach to the relationship has been found to influence relationship quality. But what does it take to engage a young person in such a relationship and sustain it over time? In this paper, I draw from the research on psychotherapy and other related literatures to briefly sketch out a working model for the determinants of mentoring relationship quality and then focus in detail on one of these-the contributions of the mentor.
\end{abstract}

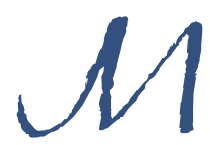

entoring has become a popular approach to promoting positive developmental outcomes for youth and mentoring programs have enjoyed exponential growth in recent decades. It is generally believed that mentoring delivered in many different formats and settings can be beneficial to youth of varying ages and evidence for the broad-based effectiveness of mentoring is indeed mounting. Most notably, a recent meta-analysis of evaluations of mentoring programs in the United States found that mentored youth demonstrated positive gains in a wide range of social, emotional, behavioral, and academic outcomes whereas non-mentored youth exhibited declines. Mentoring was also found to be effective across settings and with both children and adolescents (DuBois, Portillo, Rhodes, Silverthorn, \& Valentine, 2011). These findings support the commonly 
accepted wisdom that mentoring provides meaningful connections with adults that promote growth in multiple developmental domains. Such connections can create a particular kind of context that is conducive to a variety of forms of informal learning.

Another commonly held belief about mentoring is that virtually anyone can be a mentor. It is often presented as being easy, simply requiring that you be yourself and "share what you know." This sentiment, conveyed though public service campaigns and mentoring program advertisements aimed at recruiting volunteer mentors, is evident in claims such as "you don't need special skills to be a mentor," "just a willingness to listen, offer encouragement and share what you've learned about life" (Harvard Mentoring Project, 2005). Yet, research on mentoring has shown that not all mentoring relationships are beneficial and in fact poor mentoring may contribute to declines in youth functioning (Grossman \& Rhodes, 2002; Herrera et al., 2007; Karcher, 2005). The factors distinguishing more and less effective or even harmful mentoring largely hinge on the nature and quality of the relationships mentors form with their youth protégés. Specifically, the length and strength of the relationship are critical, with longer lasting relationships in which the young person feels close to or connected with the mentor getting better results (Grossman \& Rhodes, 2002; Parra, DuBois, Neville, \& Pugh-Lilly, 2002). One factor contributing to the development of higher quality relationships is the mentor's overall approach to the relationship. Mentors who invest in relationship building, especially early on, and focus on the youth's needs and interests tend to be more successful than those who are more prescriptive and prioritize the attainment of their own goals for their protégés (Morrow \& Styles, 1995). Such evidence begs the question-are there, in fact, "special skills" that are needed to be an effective mentor?

Rhodes (2002; Rhodes, Spencer, Keller, Liang, \& Noam, 2006), in her influential model of youth mentoring, posits that mentoring is at its core a relationshipbased intervention. Therefore, a relationship characterized by mutuality, trust, and empathy must form between the mentor and youth for positive change to occur. Such a relationship is thought to benefit youth through three interrelated processes: (a) enhancing social and emotional well-being, (b) promoting cognitive development through meaningful conversations, and (c) promoting identity development through role modeling and advocacy. But how does such a relationship develop and what helps to sustain it over time? This is not yet well understood.

We do, however, know quite a bit about how other types of growth-promoting relationships develop and work. As has been argued elsewhere, the psychotherapy literature, which has examined extensively the nature and quality of therapeutic 
relationships, has much to offer the field of youth mentoring (Spencer \& Rhodes, 2005; Spencer, 2004). Although there are significant differences between mentoring and psychotherapy, there are some important similarities. At the center of both is a relationship, the explicit goal of which is to foster the positive development of one of the partners. It stands to reason that some of the core elements of effective psychotherapy may be at work in effective mentoring relationships as well.

The nature and quality of psychotherapy relationships are thought to be determined by three sets of factors: (a) therapist factors, (b) client factors, and (c) the contexts surrounding and supporting the therapy relationships (Duncan, Miller, Wampold, \& Hubble, 2010). Research on these domains of influence has deepened our understanding of how different relational processes yield different outcomes. In this paper, I apply this three-domain model to mentoring and sketch out a general working model for the determinants of more and less effective relationships. I then discuss in greater detail just one of these-the contributions of the mentor. In psychotherapy, as in mentoring, the relationship is considered to be the cornerstone of the change process, as the therapeutic alliance has been found to account for a significant portion of the change achieved through therapy (Hubble, Duncan, Miller, \& Wampold, 2010; Norcross, 2010). It has even been asserted that the therapist is "the most robust predictor of outcome of any factor studied" (Hubble et al., 2010, p. 38). Simply put, some therapists are just better than others at forming an effective alliance with their clients. Likewise, I expect that some mentors are better than others at forging growth-promoting relationships with their youth protégés and that the approaches mentors take may make distinct and significant contributions to mentoring relationship quality. Identifying the qualities and practices of more effective mentors can help guide mentoring programs in the critical tasks of selecting appropriate mentors and providing effective training and support.

\section{Determinants of Mentoring Relationship Quality: A Working Model}

As noted above, relationship quality has been found to contribute significantly to the positive growth and change that can be achieved through mentoring. This is not surprising as strong, emotionally connected relationships with adults have been identified in the research on resilience and positive youth development as key contributors to psychological health and well-being in childhood and adolescence (e.g., Scales \& Leffert, 1999). Such evidence has fueled the mentoring movement and 
the exponential growth in mentoring programs. Although mentoring has generally been found to be effective, not all mentoring relationships are. Lower quality mentoring relationships have little effect and those that end prematurely may actually make matters worse for some youth (Parra et al., 2002; Grossman \& Rhodes, 2002). Unfortunately, sustaining mentoring relationships can be challenging. In national studies of mentoring effectiveness, only about half of the relationships studied appear to have met the initial program expectations for relationship length (Bernstein, Dun Rappaport, Olsho, Hunt, \& Levin, 2009; Grossman \& Rhodes, 2002; Herrera et al., 2007). Mentoring relationships, like all interpersonal relationships, are complex and the duration and strength of these relationships are influenced by multiple factors. Interpersonal relationships are generally understood to be mutually constructed and therefore are shaped by what each individual brings to the relationship (Miller \& Stiver, 1997; Tronick, 2001). Adapting models of relationship quality determinants from the study of psychotherapy and interpersonal relationships more broadly (Belsky, 1984; Duncan et al., 2010), I contend that the quality of the relationship formed between mentor and youth is likely influenced by the personal attributes and relational capacities the mentor and youth each brings to the relationship and the sources of support and stress in the contexts within which the relationship is embedded.

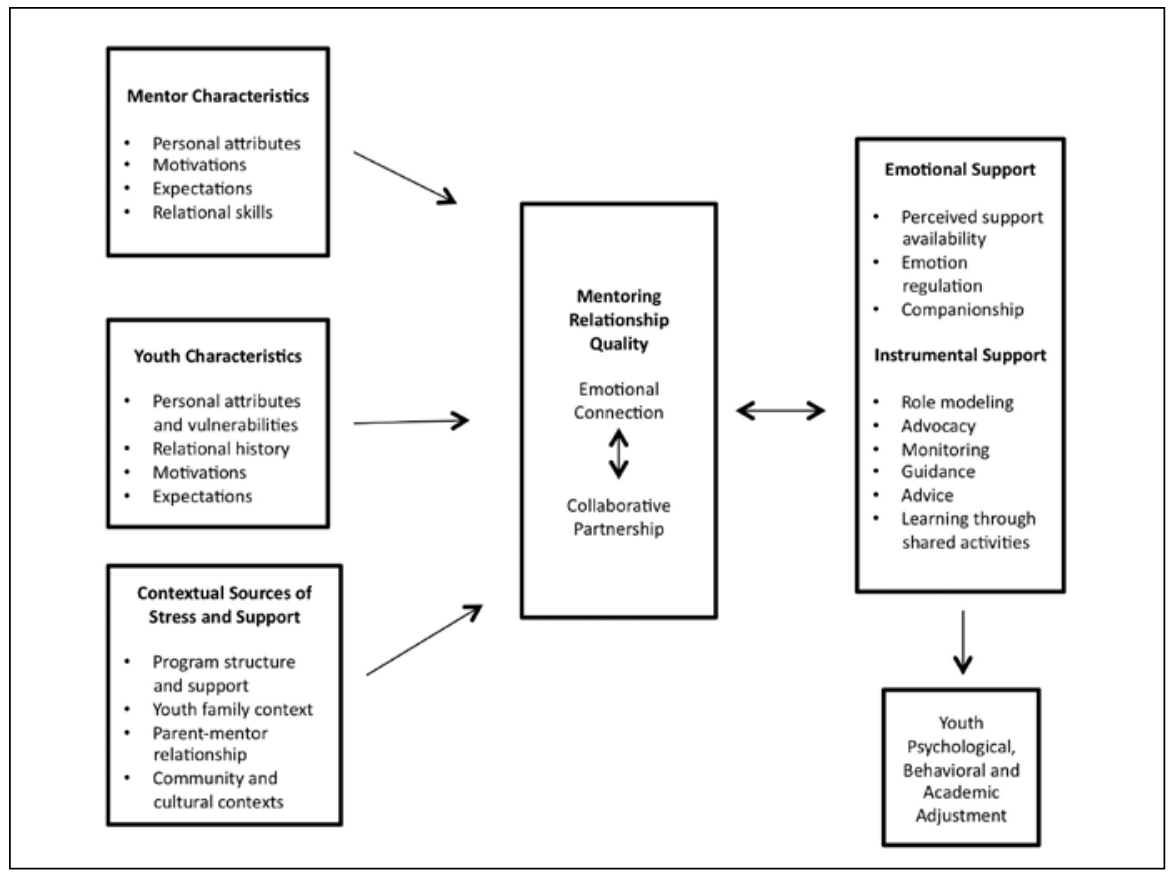

Fig. 1: Determinants of mentoring relationship quality 
In this model, it is expected that a mentor's characteristics and relational capacities will influence how the mentoring relationship develops and whether it becomes close and is sustained over time. Forging a one-to-one relationship with a young person who starts off as a stranger can be quite challenging. Mentors must have the ability to engage their protégés from the start and withstand the challenges and uncertainties that often arise in the early stages of the relationship as well as the capacity to respond to the youth's changing needs and interests as the mentoring relationship continues to develop. So too, the young person's interpersonal style and psychological and behavioral functioning at the time of the match are likely to influence whether and how a meaningful relationship is established. Young people enter into mentoring relationships with varying needs, interests, stresses, and experiences in relationships with adults. Some research indicates that these factors do matter. The nature and severity of the risks youth are experiencing at the time of match, whether they have a history of physical or sexual abuse, and the strength of their existing relationships with parents, teachers, and peers, are all factors that have been associated with mentoring relationship length and effectiveness (DuBois et al., 2011; Grossman \& Rhodes, 2002; Schwartz, Rhodes, Chan, \& Herrera, 2011). The motivations of both the mentor and youth to participate in a mentoring relationship and their expectations for it at the start are also likely to influence how the relationship develops and whether it is sustained (Spencer, 2007b). Finally, the context within which the relationship is embedded is another influential contributor. This includes program factors such as the amount and type of structure, training and ongoing support provided by the mentoring program, how the mentoring matches are made, and whether and how the young person's family is involved in the mentoring process, all of which contribute to mentoring relationship quality (DuBois, Holloway, Valentine, \& Cooper, 2002; DuBois et al., 2011).

It is within the context of a connected and collaborative relationship that growth and learning through mentoring occurs. The everyday nature of mentoring relationships coupled with consistent and ongoing contact between mentor and youth can offer a virtually endless supply of opportunities for informal learning (Spencer, 2006, 2007a; Spencer \& Liang, 2009). Engaging in shared and often fun activities with a trusted adult can enhance emotional well-being and experiencing the positive regard of a caring mentor may contribute to greater self-confidence and willingness on the part of the protégé to stretch and take risks. Mentors who come to know a good deal about the capacities and interests of the youth can intentionally structure informal activities in ways that promote learning and the development of new skills. Spending time together regularly can create openings for the mentors to provide a wide range of supports, from serving as a listening ear, to teaching a new 
skill, to encouraging youth to push themselves to try new things and then celebrating with them when they succeed or offering solace when they fall short. These processes are likely to be mutually influencing. A positive emotional connection with a caring adult may enhance feelings of trust and result in greater openness on the part of the youth protégé to the mentor's influence, support, and guidance. Likewise, receiving effective support and guidance may deepen the youth's emotional connection and feelings of trust in the mentor.

In the next section, I expand on just one component of this model and consider in greater detail the mentor's contributions to the mentoring process. The discussion here is centered primarily on one-to-one mentoring relationships. However, some of the factors considered here are likely to apply to group mentoring relationships as well.

\section{Mentors' Contributions: Personal Attributes and Relational Skills}

\section{Personal Attributes}

Research on other forms of growth-promoting relationships, including psychotherapy relationships, would suggest that the personal attributes of the mentor likely influence the quality of the mentoring relationship. Psychotherapists who are characterized by clients as being "more understanding and accepting, empathic, warm and supportive" and who "engage in fewer negative behaviors such as blaming, ignoring, or rejecting" get better results (Lambert \& Barley, 2002, p. 26). Other attributes of more effective therapists include dependability, benevolence, and responsiveness as well as the capacity to convey confidence in their ability to help (Ackerman \& Hilsenroth, 2003). Clients who experience their therapists as being invested in them also rate their relationships with their therapists more highly (Saunders, Howard, \& Orlinsky, 1989). Research on parenting, another type of growth-promoting relationship, has consistently found that parents' interactional styles play a significant role in developmental outcomes. Parental warmth and responsiveness have been associated with greater social, emotional, and cognitive competence in children (Grimes, Klein, \& Putallaz, 2004; Parke, McDowell, Kim, \& Leidy, 2006). Research on attachment has also found that the attachment style or state of mind of parents influences how they engage in relationships with their children as well as with other adults (LyonsRuth \& Jacobvitz, 2008; Zeifman \& Hazan, 2008). Relatively secure adults are better able to regulate their own emotions, can more flexibly problem-solve and cope with 
stress, and are more open to new experiences (Mikulincer, 1997; Mikulincer \& Shaver, 2008). Parents of more securely attached children tend to be more flexible, insightful, and sensitive to their children's cues (George \& Solomon, 2008). Research on attachment in adulthood has also found that adults with more secure attachment styles are better able to engage in what has been called reflective functioning, which is the capacity to consider both one's own mental states and those of others when interpreting the actions of others. Adults who are able to do this at higher levels have been found to be better able to form close and sustained relationships (Fonagy, Gergely, Jurist, \& Target, 2002).

Adults whose interpersonal styles are more conducive to the development of a close relationship are likely to be better able to form an effective mentoring relationship. Mentors who are warm and responsive may more readily engage their youth protégés in a trusting relationship. In a longitudinal study of community-based youth mentoring relationships, my colleagues and I (Spencer, Martin, Basualdo-Delmonico, Walsh, \& Jeon, 2010) found that the protégés matched with mentors whose responses on a measure of attachment style indicated greater comfort with intimacy and less anxiety in interpersonal relationships tended to report having a stronger relationship with their mentors 6-months into the relationship. In addition, the protégés of mentors who were more empathic tended to report feeling more accepted and understood by their mentor at 6-months. Mentors' motivation to become a mentor also predicted later relationship quality with mentors who volunteered out of desire to enhance their understanding of youth having stronger relationships with their protégés than mentors who did not as highly endorse this reason for volunteering (Spencer et al., 2010). Other research on peer-mentoring has found that the mentors' general attitudes about young people matter as well, with more negative mentors having the potential to contribute to decrements in youth functioning (Karcher, Davidson, Rhodes, \& Herrera, 2010) and those with higher levels of social interest and general caring for the welfare of others being more likely to persist in the mentoring relationship, even with more interpersonally challenging protégés (Karcher \& Lindwall, 2003).

We know that in order for a mentoring relationship to be effective it must last a reasonable length of time, with some research indicating it takes a year or more for the benefits to accrue (Grossman \& Rhodes, 2002; Herrera et al., 2007). However, many mentoring relationships end early, often because the mentor no longer wants to continue, and a small but significant portion of mentors abandon their mentees altogether, disappearing without saying goodbye or formally ending the relationship (Spencer, 2007b). A critical difference between mentoring and psychotherapy is that mentors are typically volunteers and do not have a professional imperative to 
persist in the face of challenges. Most mentors appear to enter the relationship for similar reasons, typically out of a stated desire to "make a difference," and have the expectation they will be able to do so through mentoring (Spencer et al., 2010). Once the relationship is underway, however, many mentors become disillusioned, either because the relationship is not going as expected or does not seem to be as meaningful to the child as they had hoped it would be (Spencer, 2007b). Some mentors persist, adjusting their expectations and focusing their efforts on getting to know their protégés and finding ways to engage them more on their terms (Spencer et al., 2010). Mentors with more secure attachment styles in relationships and who are less prone to personalizing conflicts and other forms of disconnections may better meet the challenges and conflicts that arise in the relationship with openness and flexibility, thereby avoiding creating or deepening a rift and instead promoting the development of the relationship.

In addition to persisting in the relationship over time, being dependable is also important. In one study (Karcher, 2005), declines in self-esteem were observed among youth matched with mentors whose attendance was more inconsistent, even when the relationship lasted the initially agreed upon amount of time. Mentors who show up sporadically are not likely to foster trust and confidence in the relationship. Youth, especially those who have experienced disruptions in their important relationships with adults, need to be able to count on their mentors to keep their promises. Building a personal relationship with a young person requires investing time in seeing them regularly in order to become and continue to be a meaningful person in their lives. Too often mentors underestimate the importance of the scheduled meetings to their protégés and the disappointment that missed meetings can engender.

Finally, given the central role that race, ethnicity, and culture play in developmental processes more generally (e.g., Greenfield, Keller, Fuligni, \& Maynard, 2003), similarities and differences in the mentor's and protégé's racial and ethnic backgrounds likely have some influence on mentoring relationship quality. There can be significant differences in the economic, racial, and sociocultural backgrounds of the adult volunteers and youth protégés (MENTOR, 2006). Mentors' openness and ability to understand culturally based experiences of youth whose backgrounds are different from their own and to connect across these differences may facilitate the formation of a closer and more enduring mentoring relationship. The capacity for self-reflection and openness to worldviews that are different from one's own may be important, as unacknowledged prejudices can subtly affect interpersonal relationships (Cohen \& Steele, 2002). Such qualities have been found among therapists receiving higher satisfaction ratings from their clients of color (Constantine, 2002). Training models have 
been developed to foster the development of helping professionals' cultural competence, which includes cultural knowledge, skills, and personal awareness (Sue \& Sue, 2003), and this type of training is associated with greater satisfaction with the treatment process among clients of color (Constantine, 2002). Sánchez and Colón (2005) have recommended that programs provide cultural competency training for mentors that includes instruction on how to provide feedback to ethnic minority protégées in ways that foster their trust and make them feel supported rather than judged.

\section{Relational Skills}

In addition to personal attributes, mentors' relational skills, or their abilities to form and sustain a growth-promoting relationship with a young person, are likely critical as well. Research on mentoring and other forms of adult-youth relationships, such as those formed in after-school settings, has indicated that the most effective adults are those that are emotionally engaged and provide a balance of appropriate structure, challenge, and support (Larose, Cyrenne, Garceau, Brodeur, \& Tarabulsky, 2010; Larson, 2006; Langhout, Rhodes, \& Osborne, 2004). The research on psychotherapy would suggest that mentors who are able to be empathic and authentic and convey unconditional positive regard to their protégés would be more likely to develop this kind of relationship. Therapists who engage their clients in these ways are better able to establish a treatment alliance, defined as the "quality and strength of the collaborative relationship between client and therapist" (Norcross, 2010, p. 120). The alliance comprises both the emotional bond and the agreement on the focus or goals of therapy between the therapist and client, achieved through a client-centered collaborative process (Horvath \& Greenberg, 1994; Norcross, 2010). Therapists who form strong alliances make an early investment in relationship building and pay particular attention to nurturing the emotional bond in the initial phase of treatment. They are also open and empathic, employ effective communication skills, solicit their clients' goals, and do not engage in hostile interactions such as blaming, ignoring, or rejecting their clients (Norcross, 2010). Like effective therapists, effective mentors may be those who are able to form emotionally engaged and collaboratively constructed youth-focused relationships with their protégés.

\section{Empathy, authenticity, and positive regard.}

In Rhodes' (2002) model of mentoring, a trusting, empathic, and mutual relationship is considered necessary for mentoring to be effective. Extensive research on the psychotherapy relationship has found that therapists who are able to engage their clients in an empathic and authentic way and who convey a feeling of positive regard for their clients are more effective (Norcross, 2010). Empathy can be thought of most 
simply as the ability and willingness to understand and relate to another's experience from his or her own point of view (Ackerman \& Hilsenroth, 2003; Norcross, 2010). Higher levels of perceived therapist empathy have been found to be associated with a greater likelihood of staying in treatment and the formation of a stronger treatment alliance (Bohart, Elliott, Greenberg, \& Watson, 2002). It is also thought to be linked with better outcomes in therapy through facilitating feelings of safety, which encourages greater self-disclose on the part of the client, promoting meaning-making, and activating the client's own self-healing capacities (Bohart et al., 2002). Authenticity, or the therapist's genuine presence in the relationship, facilitates the change process as well (Rogers, 1959). It is thought that when clients experience their therapist as being genuinely present and engaged, rather than putting up a façade or playing a role, they themselves are then less cautious and more honest in the relationship. Finally, positive regard is the therapist's warm acceptance of the client's experience without conditions (Norcross, 2010), which communicates that he or she is of worth and that his or her thoughts, feelings, opinions, and ideas matter. In addition to helping the client, positive regard helps the therapist to consider negative behaviors and feelings exhibited by the client within the larger context of the individual's experiences, which can make it easier to stay connected with the client during difficult moments in the psychotherapy process. Together, empathy, authenticity, and positive regard are thought to contribute to the formation of a positive bond by making the client feel listened to and understood (Rogers, 1959; Lambert \& Barley, 2002).

Research on youth mentoring suggests that mentors who are capable of engaging with their protégés in these ways may be better able to form strong and lasting mentoring relationships. In a qualitative study of enduring relationships, authenticity, empathy, and positive regard were core features of the close relationships that had been established (Spencer, 2006). In contrast, some of the mentors in a qualitative study of relationships that ended early were quite judgmental of the young person and of his or her family and found it difficult to connect with their protégés' own understandings of their experiences (Spencer, 2007b). In studies of natural mentoring relationships among transitioning and former foster care youth, empathy, authenticity, and positive regard were all salient in the youth's descriptions of their positive mentoring experiences (Ahrens et al., 2011; Munson, Smalling, Spencer, Scott, \& Tracy, 2010). Larose and colleagues (2010) found that even in a more structured program with a prescribed goal, in this case, retention of first-year university students in science and engineering majors, mentors who were perceived by their protégé as more highly emotionally engaged got better results. 
Mentors with these relational capacities may also be better able to respond to challenges that arise. Miscommunications and misunderstandings are inevitable in any interpersonal relationship and mentoring relationships are no exception. When left unaddressed, even relatively minor disruptions can contribute to the erosion of the relationship over time. Mentors who are able to step out of their own emotional experiences and consider these situations from their mentees' perspective would be better able to identify and work to repair these disconnections. Such mentors may also view these occurrences as opportunities to increase their knowledge and understanding of their protégé and further strengthen the relationship.

\section{Collaboration.}

More effective mentors are also likely those who are able to engage their protégés in the collaborative construction of their relationship, termed "authorship" by Karcher and Nakkula (2010). When mentors and youth jointly negotiate the focus, purpose, and activities of the relationship, the relationship is more apt to become developmental in nature. Research has indicated that mentors who are more prescriptive in their approach and who allow their own goals for the youth to dominate the relationship are not as effective (Morrow \& Styles, 1995). Joining with youth in collaboratively shaping the relationship offers them the opportunity to experience appropriate levels of power and control in the mentoring relationship and may contribute to their well-being by fostering feelings of efficacy and competence (Prilleltensky, Nelson, \& Peirson, 2001). Although mentors inherently bear greater responsibility for setting the frame for and maintaining the relationship (Rhodes, Liang, \& Spencer, 2009), there are many ways in which they can appropriately foster collaborative partnerships that are beneficial to the youth. Even when the goals are prescribed by the program, the mentor and youth can jointly determine how these goals are to be achieved (Karcher \& Nakkula, 2010).

In addition, researchers studying the development of cognitive abilities (e.g., Vygotsky, 1978; Rogoff, 1990) have emphasized the centrality of mutual engagement in everyday interactions with more skilled partners in children's learning. Collaborative mentoring relationships offer a multitude of opportunities for this type of joint engagement and collaborative learning. More successful mentors, like more successful psychotherapists, may be those who are able to appropriately loosen the reins on the relationship and create an environment in which they are working together with their protégés toward mutually determined goals and purposes. Further, mentors whose focus is on the promotion of the youth's development, rather than on changing or "fixing" the young person, may be better able to engage youth in collaborative relationships that are also more productive. Such mentors would recognize 
and build on the protégé's strengths and seek out opportunities to capitalize on these strengths and nurture the youth's development. Larson (2006) has suggested that a youth-driven approach to positive development requires engaging the young person's intrinsic motivation to grow and encouraging its activation and sustainment in pro-social directions in various domains of development. To be truly growth-promoting, in this view, mentors would not just support young people towards their selfidentified goals, but at times also push them to stretch and guide them towards paths that will lead to healthier and more productive futures.

\section{Summary.}

Although the personal qualities and relational skills of mentors have been discussed separately here, they likely work together and build on one another. Mentors who are more empathic would be more apt to identify accurately the needs of their mentees and thus the support they offer would prove more useful. In addition, youth who experience their mentors as empathic, authentic, and who feel that their mentors regard them in a positive light may be more likely to begin to share their vulnerabilities with their mentors. They may also be more open to assistance that is offered and perhaps also more likely to seek out or ask for assistance from their mentors. Youth who have a history of conflicted relationships with adults, and who may have given up hope that adult assistance can be of value to them, may become more willing to accept such assistance when provided in the context of a trusting, caring, and collaborative relationship. For others, a trusted adult who has engaged in activities of interest to the youth may in turn be able to encourage the youth's development in areas that the mentor recognizes as important but in which the youth may be less interested at first. Research does indicate that mentoring relationships that tend to be centered exclusively on either the emotional connection or on more goal-directed activities are less likely to promote positive outcomes for the protégés (LaRose et al., 2010; Langhout et al., 2004). An emotionally engaged relationship appears to contribute to the potency of the instrumental, goal-focused activities and perhaps youth are more open to engaging in goal-focused activities with adults they trust and whom they believe know them and view them favorably.

\section{Conclusion}

Given the rapid and continuing proliferation of mentoring programs, and the evidence that mentoring may sometimes cause harm to already vulnerable youth, it is imperative that we further our understanding of the determinants of effective 
mentoring relationships. The perhaps long list of qualities and skills delineated here may be disheartening to programs that already face significant challenges recruiting enough adult volunteers to serve as mentors. However, selecting mentors who are willing and able to go the distance with their youth protégés is critical for program success. We know that mentors who have experience working with young people in some capacity tend to do better (DuBois et al., 2002; Grossman, Chan, Schwartz, \& Rhodes, 2012). This may be partly attributable to their natural skills, but the training and support these adults may have received could also play a role. Some of the interactional styles described here may be teachable. In addition to screening mentors, training mentors in how to engage youth effectively in growth-promoting relationships could serve to enhance program effectiveness. That said, unlike the sentiment expressed in many efforts to promote youth mentoring, it is unlikely that every adult is well suited to be a mentor and programs should err on the side of being more rather than less selective.

In so doing, it is also important to take into account the great diversity in the structures and purposes of mentoring programs, as some program models require much more of mentors than others. Mentors in community-based mentoring programs, wherein mentors and youth set their own schedules and the activities of the relationship are carried out in the community, are largely on their own and the relationship hinges on the mentor's ability to forge an emotional bond with the youth. In many instances, community-based mentors are called on to persist when abrupt changes occur in their protégés' lives, such as an unplanned move or loss of telephone service, which can make it difficult to plan and carry out the expected meetings. In contrast, in school or other site-based mentoring programs mentors are relieved of the responsibility of determining where and when the mentoring will take place and are less affected by changes in the protégés' lives. However, they must still find ways to engage the young person in a one-to-one relationship, albeit under more controlled conditions. This is not to suggest that all mentoring relationships must become close personal bonds. Many programs offer quite structured and time-limited relationships and get good results (e.g., Elledge, Cavell, Ogle, \& Newgent, 2010; Taussig \& Culhane, 2010). However, the mentor must still be able to engage the youth in some way. Programs should seek to identify the key skills mentors need to implement their program model and recruit mentors whose qualities and skills match the demands of the program. It is also important to provide mentors with the training and ongoing support needed to ensure that they are well equipped to meet the demands of their roles and responsibilities. 
As discussed at the beginning of the paper, the contributions of the mentor are clearly not the sole determinant of mentoring relationship quality. What mentors bring to the relationship is important but so are the contributions of the youth and the nature of the contextual supports and stresses, with mentoring programs playing a highly influential role. Considering the contributions of the mentor is just a start. Moreover, although the ideas presented here stand on the foundation of existing research on mentoring, further research is needed to determine whether they hold true. It will be important to determine whether mentor characteristics do in fact make a distinct contribution to mentoring relationship quality and, if so, to identify which qualities and relational skills make the most difference. Also, understanding whether mentor training directed towards enhancing the relational skills outlined here promotes the development of more effective relationships could provide important guidance for mentoring programs in their efforts to prepare and support mentors.

The rewards of mentoring can be great, but so too are the risks. Mentoring is proving to be a powerful and flexible tool in the promotion of positive development for youth (DuBois et al., 2011). These relationships can provide a multitude of opportunities for informal learning, as mentors can step in and both join and guide youth in the continuous process of further developing their social, emotional, behavioral, and academic skills and capacities. Such learning, however, appears to be dependent on the nature and quality of the relationship that forms between mentor and youth and thus relies heavily on the ability of mentors to meaningfully engage their protégés. Rapid expansions in the number and size of mentoring programs have contributed to programs feeling pressured to match as many youth as possible, often with a limited pool of available mentors. Fortunately, the tide is turning and more attention is being paid to the quality of mentoring relationships. Greater consideration of the mentor's contribution to relationship quality is needed to ensure that the mentoring relationships programs provide make a positive difference in the lives of the youth served.

\section{References}

Ackerman, S. J., \& Hilsenroth, M. J. (2003). A review of therapist characteristics and techniques positively impacting the therapeutic alliance. Clinical Psychology Review, 23(1), 1-33.

Ahrens, K., DuBois, D. L., Garrison, M., Spencer, R., Richardson, L. P., \& Lozano, P. (2011). Qualitative exploration of relationships with important non-parental adults in the lives of youth in foster care. Children \& Youth Services Review, 33, 1012-1023.

Belsky, J. (1984). The determinants of parenting: A process model. Child Development, 55(1), 83-96.

Bernstein, L., Dun Rappaport, C., Olsho, L., Hunt, D., \& Levin, M. (2009). Impact evaluation of 
the U.S. Department of Education's Student Mentoring Program (NCEE 2009-4047). Washington, DC: National Center for Education Evaluation and Regional Assistance, Institute of Education Sciences, U.S. Department of Education. Retrieved April 25, 2012, from http://ies.ed.gov/ncee/

Bohart, A. C., Elliott, R., Greenberg, L., \& Watson, J. C. (2002). Empathy. In J. C. Norcross (Ed.), Psychotherapy relationships that work: Therapist contributions and responsiveness to patients (pp. 89-108). New York: Oxford University Press.

Cohen, G. L., \& Steele, C. M. (2002). A barrier of mistrust: How negative stereotypes affect cross-race mentoring. In J. Aronson (Ed.), Improving academic achievement: Impact of psychological factors on education ( $\mathrm{pp}$. 303-327). San Diego, CA: Academic Press.

Constantine, M. G. (2002). Predictors of satisfaction with counseling: Racial and ethnic minority clients' attitudes toward counseling and ratings of their counselors' general and multicultural counseling competence. Journal of Counseling Psychology, 49(2), 255-263.

DuBois, D. L., Holloway, B. E., Valentine, J. C., \& Cooper, H. (2002). Effectiveness of mentoring programs for youth: a meta-analytic review. American Journal of Community Psychology, 30(2), 157-197.

DuBois, D. L., Portillo, N., Rhodes, J. E., Silverthorn, N., \& Valentine, J. C. (2011). How effective are mentoring programs for youth? A systematic assessment of the evidence. Psychological Science in the Public Interest, 12(2), 57-91.

Duncan, B. L., Miller, S. D., Wampold, B. E., \& Hubble, M. A. (2010). The heart and soul of change: Delivering what works in therapy (2nd ed.). Washington, DC: American Psychological Association.

Elledge, L. C., Cavell, T. A., Ogle, N. T., \& Newgent, R. A. (2010). School-based mentoring as selective prevention for bullied children: A preliminary test. The Journal of Primary Prevention, 31(3), 171-187.

Fonagy, P., Gergely, G., Jurist, E., \& Target, M. (2002). Affect regulation, mentalization, and the development of the self. New York: Other Press.
George, C., \& Solomon, J. (2008). The caregiving system: A behavioral systems approach to parenting. In J. Cassidy \& P. R. Shaver (Eds.), Handbook of attachment: Theory, research, and clinical applications (2nd ed.) (pp. 833-856). New York: Guilford Press.

Greenfield, P. M., Keller, H., Fuligni, A., \& Maynard, A. (2003). Cultural pathways through universal development. Annual Review of Psychology, 54, 461-490.

Grimes, C. L., Klein, T. P., \& Putallaz, M. (2004). Parents' relationships with their parents and peers: Influences on children's social development. In J. B. Kupersmidt \& K. A. Dodge (Eds.), Children's peer relations: From development to intervention ( $\mathrm{pp}$. 141-158). Washington, DC: American Psychological Association.

Grossman, J. B., Chan, C., Schwartz, S., \& Rhodes, J. E. (2012). The test of time in school-based mentoring: The role of relationship duration and re-matching on academic outcomes. American Journal of Community Psychology, 49, 43-54.

Grossman, J. B., \& Rhodes, J. E. (2002). The test of time: Predictors and effects of duration in youth mentoring programs. American Journal of Community Psychology, 30, 199-219.

Harvard Mentoring Project. (2005, January). Advertisement for National Mentoring Month. Retrieved April 25, 2012, from http://www.hsph.harvard.edu/chc/wmy/ $\mathrm{nmm} /$ year_four_report.html\#print.

Herrera, C., Grossman, J. B., Kauh, T. J., Feldman, A. F., McMaken, J., \& Jucovy, L. Z. (2007). Making a difference in schools: The Big Brothers Big Sisters School-Based Mentoring Impact Study. Philadelphia: Public/ Private Ventures.

Horvath, A. (Ed.), \& Greenberg, L. (Ed.). (1994). The working alliance: Theory, research, and practice. Oxford England: John Wiley \& Sons.

Hubble, M. A., Duncan, B. L., Miller, S. D., \& Wampold, B. E. (2010). Introduction. In B. L. Duncan, S. D. Miller, B. E. Wampold, \& M. A. Hubble (Eds.), The heart and soul of change: Delivering what works in therapy. (2nd ed.) (pp. 23-46). Washington, DC: American Psychological Association. 
Karcher, M. J. (2005). The effects of schoolbased developmental mentoring and mentors' attendance on mentees' selfesteem, behavior, and connectedness. Psychology in the Schools, 42, 65-77.

Karcher, M. J., Davidson, A. J., Rhodes, J. E., \& Herrera, C. (2010). Pygmalion in the program: The role of teenage peer mentors' attitudes in shaping their mentees' outcomes. Applied Developmental Science 14(4), 212-227.

Karcher, M. J., \& Lindwall, J. (2003). Social interest, connectedness, and challenging experiences: What makes high school mentors persist?. The Journal of Individual Psychology, 59(3), 293-315.

Karcher, M. J., \& Nakkula, M. J. (2010). Youth mentoring with a balanced focus, shared purpose, and collaborative interactions. New Directions for Youth Development, 2010, 13-32.

Lambert, M. J., \& Barley, D. E. (2002). Research summary on the therapeutic relationship and psychotherapy outcome. In J. C. Norcross (Ed.), Psychotherapy relationships that work: Therapist contributions to responsiveness to patients (pp. 17-32). New York: Oxford University Press.

Langhout, R. D., Rhodes, J. E., \& Osborne, L. (2004). An exploratory study of youth mentoring in an urban context: Adolescents' perceptions of relationship styles. Journal of Youth and Adolescence, 33, 293-306.

Larose, S., Cyrenne, D., Garceau, O., Brodeur, P., \& Tarabulsy, G. M. (2010), The structure of effective academic mentoring in late adolescence. New Directions for Youth Development, 2010, 123-140.

Larson, R. (2006). Positive youth development, willful adolescents, and mentoring. Journal of Community Psychology, 34(6), 677689.

Lyons-Ruth, K., \& Jacobvitz, D. (2008). Attachment disorganization: Genetic factors, parenting contexts, and developmental transformation from infancy to adulthood. In J. Cassidy \& P. R. Shaver (Eds.), Handbook of attachment: Theory, research, and clinical applications (2nd ed.) ( $p$ p. 666-697). New York: Guilford Press.
MENTOR/National Mentoring Partnership. (2006). Mentoring in America 2005: A snapshot of the current state of mentoring. Alexandria, VA: Author.

Mikulincer, M. (1997). Adult attachment style and information processing: Individual differences in curiosity and cognitive closure. Journal of Personality and Social Psychology, 72(5), 1217-1230.

Mikulincer, M., \& Shaver, P. R. (2008). Adult attachment and affect regulation. In J. Cassidy \& P. R. Shaver (Eds.). Handbook of attachment: Theory, research, and clinical applications (2nd ed.) (pp. 503-531). New York: Guilford Press.

Miller, J. B., \& Stiver, I. P. (1997). The healing connection. Boston: Beacon Press.

Morrow, K. V., \& Styles, M. B. (1995). Building relationships with youth in program settings: A study of Big Brothers/Big Sisters. Philadelphia: Public/Private Ventures.

Munson, M. R., Smalling, S., Spencer, R., Scott, L. D., \& Tracy, E. (2010). A steady presence in the midst of change: Natural mentors in the lives of older youth exiting foster care. Children \& Youth Services Review, 32, 527-535.

Norcross, J. C. (2010). The therapeutic relationship. In B. L. Duncan, S. D. Miller, B. E. Wampold \& M. A. Hubble (Eds.), The heart and soul of change: Delivering what works in therapy (2nd ed.) (pp. 113-141). Washington: American Psychological Association.

Parke, R. D., McDowell, D. J., Kim, M., \& Leidy, M. S. (2006). Family and Peer Relationships: The Role of Emotion Regulatory Processes. In D. K. Snyder, J. Simpson, \& J. $\mathrm{N}$. Hughes. Emotion regulation in couples and families: Pathways to dysfunction and health (pp. 143-162). Washington, DC: American Psychological Association.

Parra, G. R., DuBois, D. L., Neville, H. A., \& PughLilly, A. O. (2002). Mentoring relationships for youth: Investigation of a process-oriented model. Journal of Community Psychology, 30(4), 367-388.

Prilleltensky, I., Nelson, G., \& Peirson, L. (2001). The role of power and control in children's lives: An ecological analysis of 
pathways toward wellness, resilience and problems. Journal of Community \& Applied Social Psychology, 11(2), 143-158.

Rhodes, J. E. (2002). Stand by me: The risks and rewards of mentoring today's youth. Cambridge, MA: Harvard University Press.

Rhodes, J. E., Liang, B., \& Spencer, R. (2009). "First, do no harm": A call for ethical guidelines in youth mentoring. Professional Psychology: Research and Practice, 40(5), 452-458.

Rhodes, J. E., Spencer, R., Keller, T. E., Liang, B., \& Noam, G. (2006). A model for the influence of mentoring relationships on youth development. Journal of Community Psychology, 34(6), 691-707.

Rogers, C. R. (1959). A theory of therapy, personality and interpersonal relationships. In S. Koch (Ed.), Psychology: A study of a science (pp. 184-256). New York: McGrawHill.

Rogoff, B. (1990). Apprenticeship in thinking: Cognitive development in social context. New York: Oxford University Press.

Sánchez, B., \& Colón, Y. (2005). Race, ethnicity, and culture in mentoring relationships. In D. L. Dubois \& M. J. Karcher (Eds.). Handbook of youth mentoring (pp. 191-204). Thousand Oaks, CA: Sage Publications.

Saunders, S. M., Howard, K., \& Orlinksy, D. E. (1989). The Therapeutic Bond Scales: Psychometric characteristics and relationship to treatment effectiveness. Psychological Assessment: A Journal of Consulting and Clinical Psychology, 1(4), 323-330.

Scales, P. C., \& Leffert, N. (1999). Developmental assets: $A$ synthesis of the scientific research on adolescent development. Minneapolis: Search Institute.

Schwartz, S. E. O., Rhodes, J. E., Chan, C. S., \& Herrera, C. (2011). The impact of schoolbased mentoring on youths with different relational profiles. Developmental Psychology, 47(2), 450-462.

Spencer, R. (2004). Studying relationships in psychotherapy: An untapped resource for youth mentoring. New Directions in Youth Development: Theory, Practice and Research, 103, 31-43.
Spencer, R. (2006). Understanding the mentoring process between adolescents and adults. Youth and Society, 37(3), 287-315.

Spencer, R. (2007a). "I just feel safe with him": Close and enduring male youth mentoring relationships. Psychology of Men and Masculinity, 8(3), 185-198.

Spencer, R. (2007b). "It's not what I expected": A qualitative study of youth mentoring relationship failures. Journal of Adolescent Research, 22, 331-354.

Spencer, R., \& Liang, B. (2009). "She gives me a break from the world": Formal youth mentoring relationships between adolescent girls and adult women. Journal of Primary Prevention, 30, 109-130.

Spencer, R., Martin, N. C., Basualdo-Delmonico, A., Walsh, J., \& Jeon, S. M. (2010, November). Youth mentoring relationships: The role of mentor expectations and characteristics in relationship closeness and duration. Poster presented at 138th American Public Health Association Annual Meeting, Denver, CO.

Spencer, R., \& Rhodes, J. E. (2005). A counseling and psychotherapy perspective on mentoring relationships. In D. L. Dubois \& M. J. Karcher (Eds.). Handbook of youth mentoring (pp. 118-132). Thousand Oaks, CA: Sage Publications.

Sue, D., \& Sue, D. (2003). Counseling the culturally diverse: Theory and practice (4th ed.). Hoboken, NJ: John Wiley \& Sons Inc.

Taussig, H. N., \& Culhane, S.E. (2010). Impact of a mentoring and skills group program on mental health outcomes for maltreated children in foster care. Archives of Pediatrics \& Adolescent Medicine, 164(8), 739-746.

Tronick, E. Z. (2001). Emotional connections and dyadic consciousness in infant-mother and patient-therapist interactions. Psychoanalytic Dialogues, 11(2), 187-194.

Vygotsky, L. S. (1978). Mind in society. Cambridge, MA: Harvard University Press.

Zeifman, D., \& Hazan, C. (2008). Pair bonds as attachments: Reevaluating the evidence. In J. Cassidy \& P. R. Shaver (Eds.). Handbook of attachment: Theory, research, and clinical applications (2nd ed.). New York: Guilford Press. 


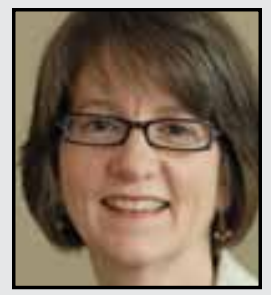

Renée Spencer Ed.D., LICSW, is an Associate Professor at the Boston University School of Social Work. Her research, largely qualitative, focuses on youth mentoring, specifically relational processes in more and less successful relationships. As a recipient of a William T. Grant Foundation Scholar Award, she conducted a mixed-methods longitudinal study of the development of youth mentoring relationships in communitybased programs. She has published widely on youth mentoring and serves as a member of several boards and committees, including MENTOR/National Mentoring Partnership Research and Policy Council and The Center for the Advancement of Mentoring (TCAM) National Cadre of Mentoring Researchers.

\section{LINKTO:}

http://www.bu.edu/ssw/about/facultystaff/faculty/spencer 